\title{
Design and analysis of interior composite-rotor bearingless permanent magnet synchronous motors with two layer permanent magnets
}

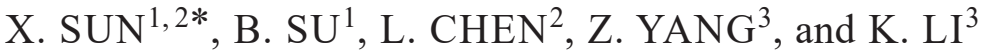 \\ ${ }^{1}$ School of Automotive and Traffic Engineering, Jiangsu University, Zhenjiang, 212013, China \\ ${ }^{2}$ Automotive Engineering Research Institute, Jiangsu University, Zhenjiang, 212013, China \\ ${ }^{3}$ School of Electrical and Information Engineering, Jiangsu University, Zhenjiang 212013, China
}

\begin{abstract}
In this paper, a new type of interior composite-rotor bearingless permanent magnet synchronous motors (BPMSMs) with two layer permanent magnets (PMs) is proposed. In order to reduce the torque ripple of this kind of motors, the sizes of PMs are optimized. Moreover, the magnetic field analysis of the interior composite-rotor BPMSM with two layer PMs is carried out by the finite element method (FEM). The corresponding static electronic magnetic characteristics at no load, including magnetic field, PM flux linkage and inductance, are studied in detail. In addition, electromagnetic torque characteristics and suspension force characteristics are also investigated thoroughly. The results of the analysis and simulation lay a significant foundation for further research on the interior composite-rotor BPMSMs with two layer PMs.
\end{abstract}

Key words: bearingless motor, permanent magnet motor, finite element analysis, cogging torque, static electromagnetic characteristics.

\section{Introduction}

Bearingless motors which combine the function of conventional motors and magnetic bearings [1] have some remarkable advantages in the fields of special electric drives for the higher critical speed and lower cost $[2,3]$. Thus they are suitable for many high speed drive applications, such as flywheel energy storage, compressors, turbomolecular pumps and so on [4-6].

During the past decades, many kinds of bearingless motors were proposed and carried out, for example, bearingless switched reluctance motors $[7,8]$, bearingless induction motors $[9,10]$, bearingless permanent magnet synchronous motors (BPMSMs), etc. Due to small size, no contact, no wear, no lubrication, high efficiency, the BPMSMs are highly valued around the world, especially in semiconductor, pharmaceutical and medical industry $[11,12]$. Comparing with other types of BPMSMs, the interior BPMSMs (IBPMSMs) generating both electromagnetic torque and reluctance torque can improve the power density of motors [13-15].

However, IBPMSMs have relatively high torque ripple generated by reluctance torque, which results in noise and vibration. In [16], Kim et al. introduce an optimization method for reducing the torque ripple in interior permanent magnet synchronous motors (IPMSMs) by using Taguchi method. In [17], the level set method is proposed for stator design optimum of IPMSMs. For exploring whether optimization aimed at reducing torque ripple has any effect on suspension force, an accurate suspension force mathematical model is indispensable. In [18], a mathematical model of BPMSMs is proposed,

*e-mail: xdsun@ujs.edu.cn

Manuscript submitted 2016-12-22, revised 2017-02-24 and 2017-03-23, initially accepted for publication 2017-03-24, published in December 2017. based on the magnetic circuit inductance model and virtual displacement principle. The mathematical model has sufficient precision; however, huge and complex computation is a drawback of this method. In [19], a suspension force mathematical model of the bearingless switched reluctance motors is built with Maxwell stress tensor method, and the mathematical model not only simple, but also effective, as shown in the results of the experiment.

In this paper, an interior composite-rotor BPMSM with two layer PMs is proposed. Then the electromagnetic characteristic of the proposed motor is analyzed by employing the finite element method (FEM) [20], which is used for the optimization of the motor. In Section 2, the suspension principle of proposed motor with two pole pairs of suspension windings and three pole pairs of suspension windings is introduced. In Section 3, the process of optimization based on the size of permanent magnets (PMs) is proposed, as well as the principle of optimization reducing the cogging torque and increasing the suspension force. In Section 4, the finite element model, plot mesh and prototype parameters are presented. Then the basic electromagnetic characteristics at no load including PM flux linkage, magnetic field and inductance of the proposed machine are analyzed. In Section 5, the electromagnetic characteristics are investigated. In Section 6, the suspension force characteristics are analyzed. Finally, Section 7 summarizes the paper.

\section{Suspension principle}

For generating the suspension force and electromagnetic torque simultaneously, in the BPMSMs, the torque windings and suspension windings are wound together in the same stator slots. Suppose the pole pair number and current frequency of torque windings is $P_{T}$ and $\omega_{T}$. The pole pair number and current frequency of 
suspension windings is $P_{S}$ and $\omega_{S}$. The suspension force can be generated when the following two conditions are satisfied: (1) $P_{T}=P_{S} \pm 1$, (2) $\omega_{T}=\omega_{S}$. In this paper, $P_{T}=2, P_{S}=3$.

The magnetic force in the BPMSM includes Lorentz force and Maxwell force, according to electromagnetic field theory, and the suspension force is provided by the resultant between Lorentz force and Maxwell force [12].

The principle of suspension force generated in the proposed motor is illustrated in Fig. 1. The proposed motor has two pole pairs of torque windings and three pole pairs of suspension windings. When the rotor is in the center location, the symmetric four-pole magnetic field $\Psi_{4}$ is generated by torque windings $N_{M \alpha}, N_{M \beta}$ and PMs., If the suspension windings and $N_{S \beta}$ are not excited, there is no suspension force generated, because $\Psi_{4}$ is balanced. When $N_{S \alpha}$ is excited along positive directions as shown in Fig. 1(a), the six-pole magnetic field $\Psi_{6}$ is generated by suspension windings, which together with $\Psi_{4}$ strengthen the magnetic field along the $\mathrm{x}$-axis positive directions. Therefore, the air gap flux density at position 1 is larger than position 3 , which will generate a suspension force $F_{x}$ along

a)

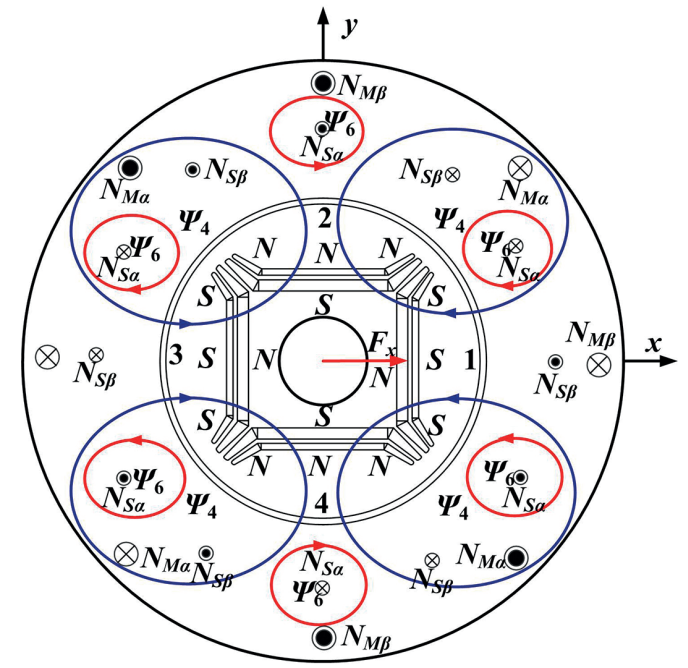

b)

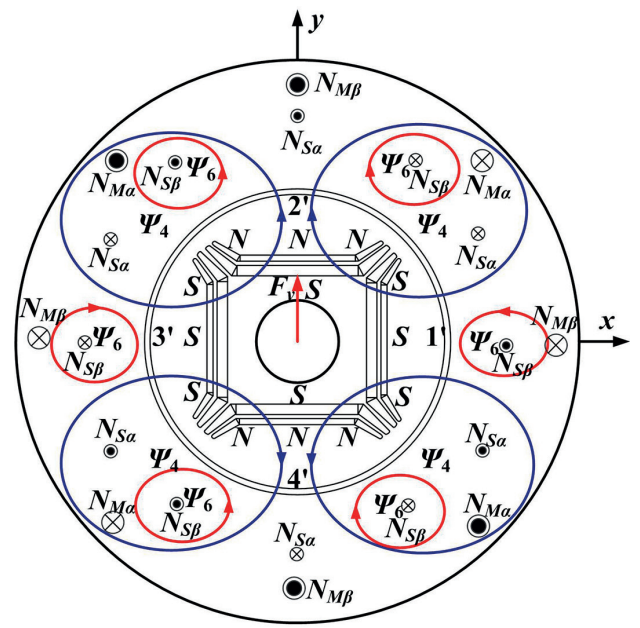

Fig. 1. Principle of suspension force, a) suspension force along x-axis, b) suspension force along y-axis the $\mathrm{x}$-axis positive direction. In contrast, the suspension force $F_{x}$ along the x-axis negative directions will be generated if reverse current is provided. Similarly, in Fig. 1(b), the suspension force $F_{y}$ along the y-axis positive directions can be produced by the suspension force winding $N_{S \beta}$ when positive current is provided for it. Therefore, based on excitation flux, the suspension force of rotor can be controlled stably by adjusting directions and amplitudes of suspension windings $N_{S \alpha}$ and $N_{S \beta}$. Briefly, rotation of the machine is mainly controlled by torque windings, and suspension of the machine is controlled by suspension windings.

\section{Optimization of cogging torque}

Due to the interaction between the permanent magnets and slotted armature lamination, the cogging torque is inevitable in slotted PM motors. This kind of torque ripple will cause noise and vibration and influence the control precision. Therefore, eliminating torque ripple is one of the most important tasks in PM motor design. In order to eliminate cogging torque, in this part, the thickness of tangential-set PMs and length of radial-set PMs are optimized by using FEM software Ansoft. The geometrical parameters of PMs are determined according to the simulation results and other factors, such as mechanical strength of rotor and manufacturing costs

In this paper, the double layer PMs are used to increase flux. The illustration of geometrical parameters of proposed double layer PMs is presented in Fig. 2. It is constructed by radial-set PMs and tangential-set PMs, and the PMs in different locations is named according to the direction of magnetic field generated by PM. As an important parameter affecting the performance of machine, the thickness of PM should be consider thoroughly. There is a certain degree of freedom when designing the double layer PMs. First, we reference the equation used in inner radial-rotor BPMSMs to estimate the thickness of double layer PMs. According to (1), the reference range of PMs thickness for proposed machine can be given as

$$
h_{M}=\frac{K_{s} K_{\alpha} b_{m 0} \delta_{0}}{\left(1-b_{m 0}\right) \sigma_{0}}
$$

where $h_{M}$ is the total thickness of double layers PMs, $K_{S}$ is the saturation coefficient of machine, $K_{\alpha}$ is the coefficient related

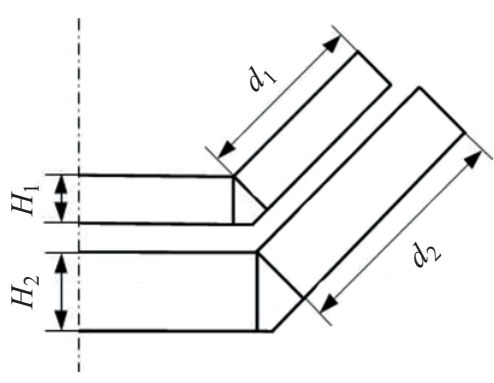

Fig. 2. Geometrical parameters of PMs 
to the structure of rotor, $b_{m 0}$ is no-load operating point of the $\mathrm{PM}, \delta_{0}$ is airgap length, $\sigma_{0}$ is no-load leakage coefficient. Then, according to the obtained reference range of PMs thickness, the thickness of the inner radial-set PMs $\mathrm{H}_{2}$ and outer radial-set PMs $H_{1}$ can be obtained. We might as well set the $H_{2}$ to $2.5 \mathrm{~mm}$ first; then, $H_{1}$ are optimized to obtain the lower cogging torque. As shown in Fig. 3, the cogging torque increases with the increase of $H_{1}$. On the other hand, it is better to choose a large value of $H_{1}$ to reduce the rejecting rate of process. Considering the irreversible demagnetization of PM in limited conditions, the value of $H_{1}$ cannot be too small. Taking all that into account, $H_{1}$ is set to $1.5 \mathrm{~mm}$ in the work.

The structure of tangential-set PMs has some remarkable advantages such as high reluctance torque and high power density, so the length of tangential-set PMs should not be too short. However, excessive length will increase the complexity

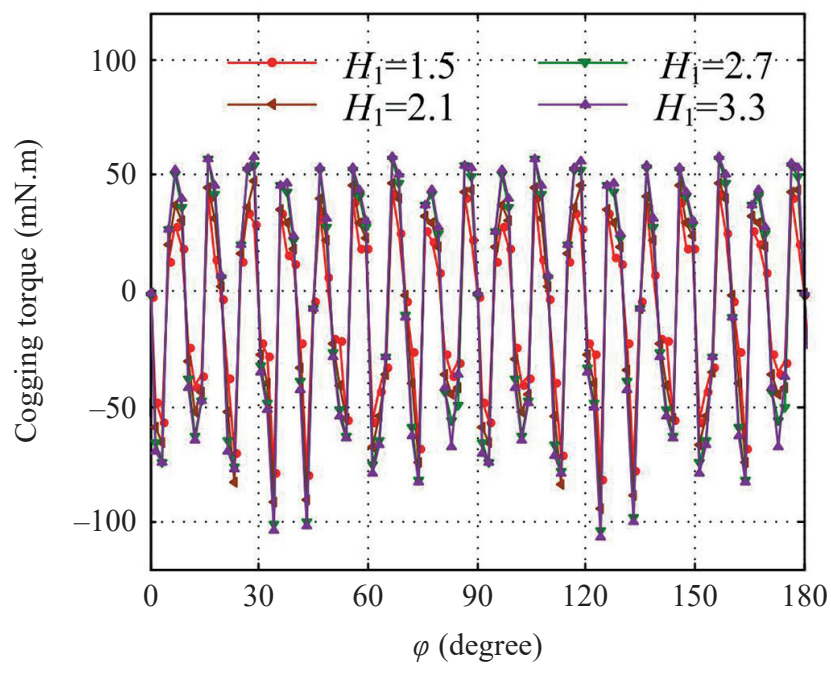

Fig. 3. Relationship between cogging torque and $H_{1}$

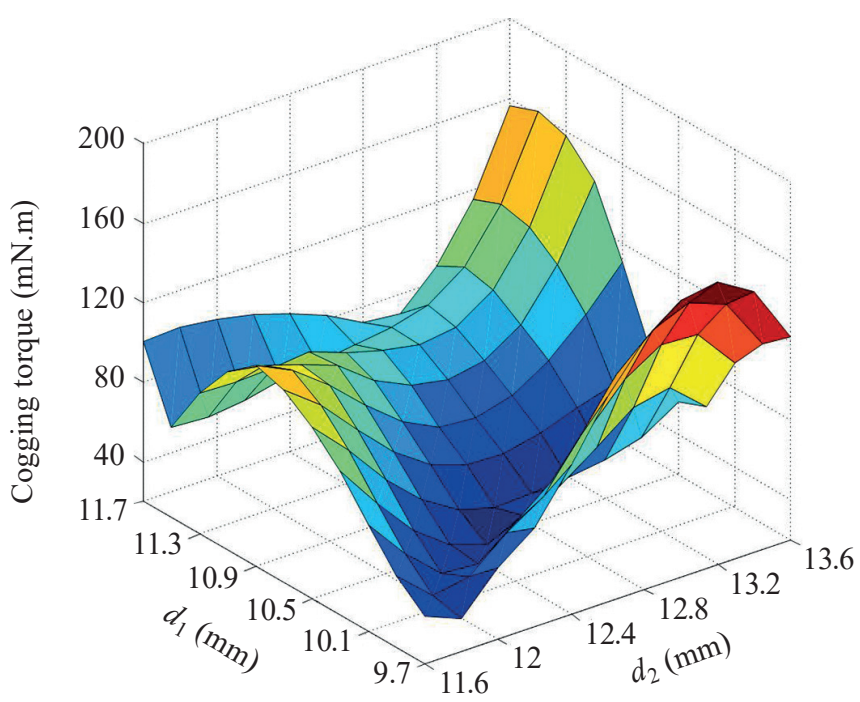

Fig. 4. Relation between cogging torque and two tangential-set PMs of the structure, manufacturing processes and manufacturing costs, furthermore the mechanical strength of rotor plate also decreases. The relationship between the cogging torque and the length of two tangential-set PMs is shown in Fig. 4. As shown in Fig. 4, the relationship between the cogging torque and two tangential-set PMs length (outer tangential-set $d_{1}$, inner tangential-set PMs $d_{2}$ ) is nonlinear. Setting $d_{1}$ and $d_{2}$ as $10.3 \mathrm{~mm}$ and $12.4 \mathrm{~mm}$, respectively, the cogging torque amplitude is 32.9 mN.m, which is the minimum value. Fig. 5 shows the cogging torque comparison of initial design and optimized design. According to Fig. 5, it is obvious that comparing with un-optimized structure, the cogging torque with optimized structure is $80 \%$ lower.

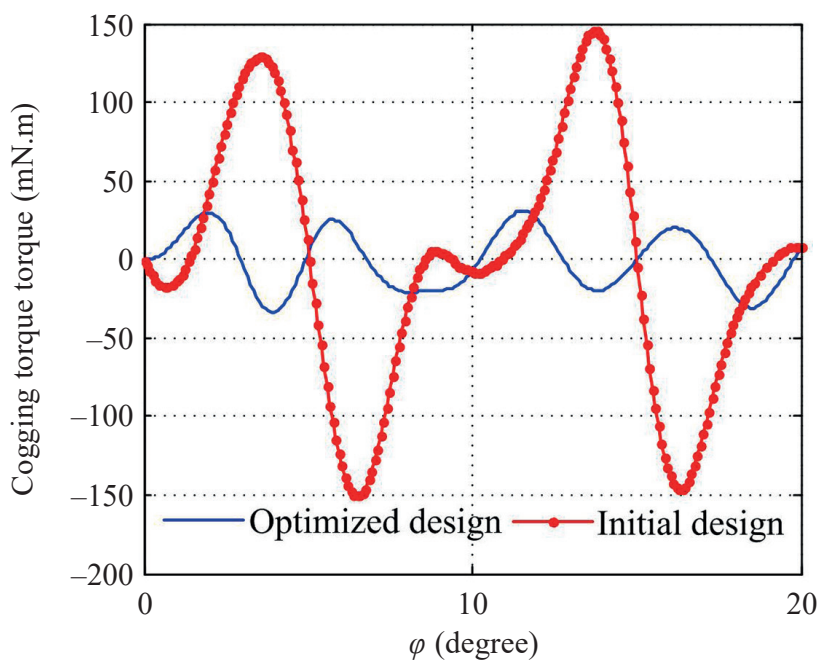

Fig. 5. Cogging torque of initial design and optimized design

The cogging torque is one of the main concerns in PM motors, and it is caused by the interaction between the PMs and core. Since there are slots in the stator, it makes the reluctance of motor distributed unevenly, which causes magnetic energy changes in the PMs. The number of periods of the cogging torque $N_{p}$ during a stator slot pitch rotation can be written as

$$
N_{p}=\frac{2 p}{\operatorname{GCD}(z, 2 p)},
$$

where $z$ is the number of the stator slots, $p$ is the number of PM pole pairs, and $\operatorname{GCD}(z, 2 p)$ represents the greatest common divisors between $z$ and $2 p$. In the proposed motor, $z$ is equal to 36 , and $p$ is equal to 2. According to (2), it can be calculated that $N_{p}$ is equal to 1 . According to Fig. 5 , it is obvious that $N_{p}$ of initial design cogging torque is 1 , and it is in agreement with the theory.

Analytical expression of the cogging torque is derived using the energy method and virtual displacement principle, and it can be written as

$$
T_{\operatorname{cog}}=\frac{\partial W}{\partial \alpha},
$$


where $W$ and $\alpha$ are magnetic energy of motor and position angle, respectively, and $W$ is approximately equal to magnetic energy in airgap and PM, which can be given as

$$
W(\alpha) \approx W_{\text {airgap }+P M}(\alpha)=\frac{1}{2 \mu_{0}} \int_{V} B^{2} \mathrm{~d} V
$$

where $\mu_{0}$ and $B$ are airgap permeability, airgap flux density, respectively, and $B$ along surface of armature can be given as follows:

$$
B(\theta, \alpha)=B_{r}(\theta) \frac{h_{m}(\theta)}{h_{m}(\theta)+\delta(\theta, \alpha)},
$$

where $B_{r}(\theta), \delta(\theta, \alpha)$ and $h_{m}(\theta)$ are PM remanence, effective airgap length and PM width along lateral surface of armature, respectively. Therefore, (4) can be written as

$$
W(\alpha)=\frac{1}{2 \mu_{0}} \int_{V} B_{r}^{2}(\theta)\left[\frac{h_{m}(\theta)}{h_{m}(\theta)+\delta(\theta, \alpha)}\right]^{2} \mathrm{~d} V .
$$

Taking Fourier expansion for $B_{r}^{2}(\theta)$ and $\left[\frac{h_{m}(\theta)}{h_{m}(\theta)+\delta(\theta, \alpha)}\right]^{2}$, and substituting (6) into (3), the cogging torque equation can be obtained

$$
T_{\operatorname{cog}}(\alpha)=\frac{\pi z L_{a}}{4 \mu_{0}}\left(R_{2}^{2}-R_{1}^{2}\right) \sum_{n=1}^{\infty} n G_{n} B_{r \frac{n z}{2 p}} \sin n z \alpha
$$

where, $L_{a}$ is axial length of armature core, $R_{2}$ is outside diameter of airgap, $R_{1}$ is inside diameter of airgap, $B_{r \frac{n z}{2 p}}$ and $G_{n}$ are Fourier coefficient when taking Fourier expansion for $B_{r}(\theta)$ and $\left[\frac{h_{m}(\theta)}{h_{m}(\theta)+\delta(\theta, \alpha)}\right]^{2}$, respectively. Furthermore, $n$ is an integer which makes $\frac{n z}{2 p}$ also as an integer, and $n_{1}$ is equal to $N_{p}$. The fast Fourier transform (FFT) for cogging torque in one pitch period is used. The results of fundamental wave and harmonics of initial design and optimized design are shown in Fig. 6 and Fig. 7, respectively.

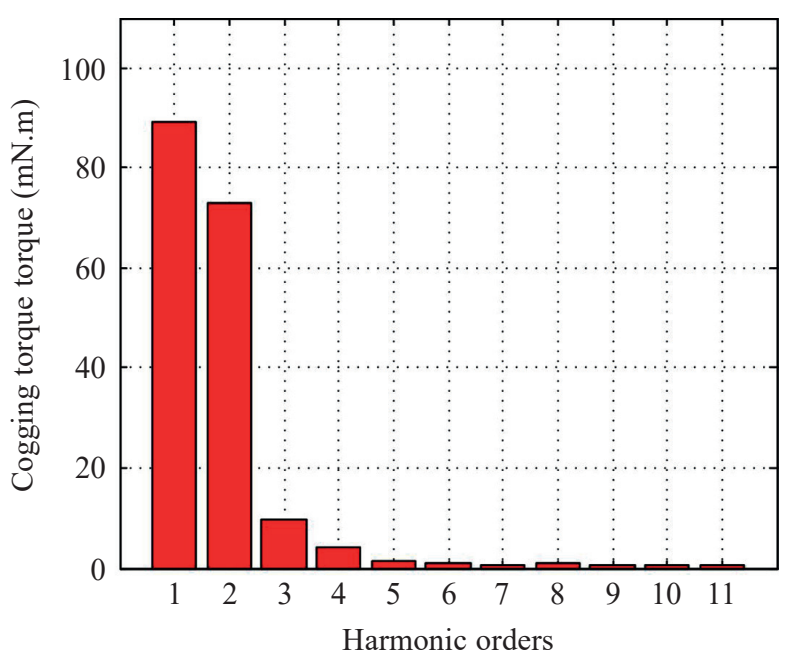

Fig. 6. Amplitude of fundamental wave and harmonics of initial design

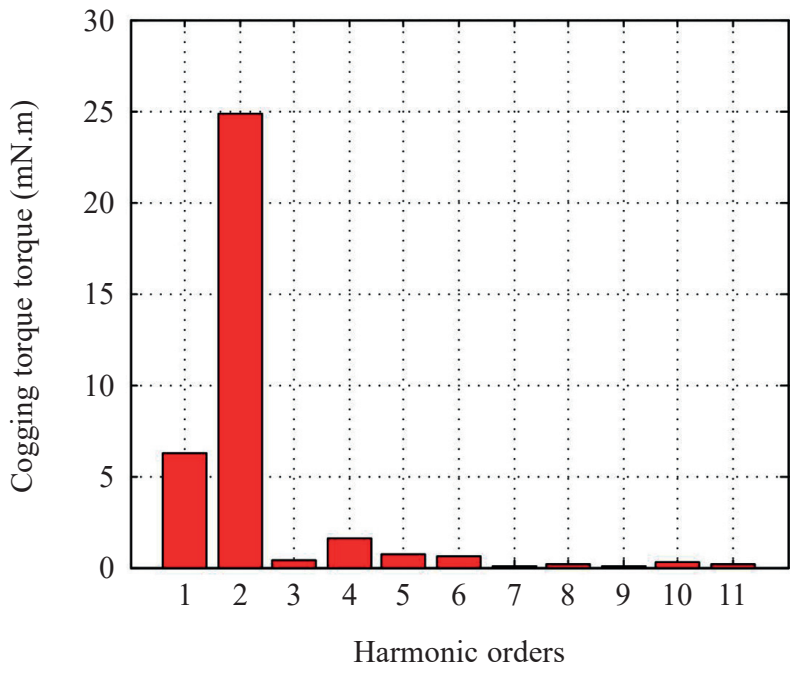

Fig. 7. Amplitude of fundamental wave and harmonics of optimized design

It can be seen from Figs. 6 and 7 that the value of fundamental amplitude is 89.2 before optimizing. However, the fundamental amplitude has reduced significantly after optimizing, and drops to 6.2. In addition, as shown in Fig. 5, the mean value of the cogging torque is close to zero, which indicates that only cogging torque causes torque ripple.

\section{Electromagnetic analysis at no load}

In this section, the finite element model, plot mesh and prototype parameters are presented. Next, the electromagnetic characteristics at no load including magnetic field, PM flux linkage and inductance of the proposed motor are presented.

4.1. Modeling and simulation. Figure 8 shows the finite element model of proposed motor. The proposed motor consists of a stator, rotor, four-pole torque windings, six-pole suspension

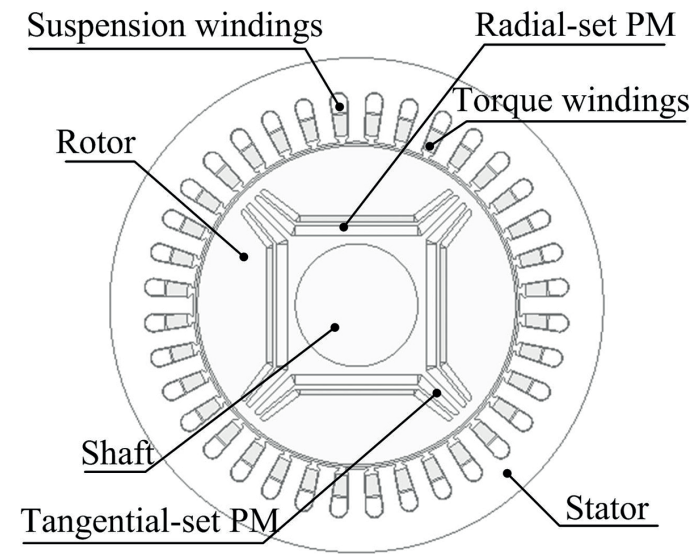

Fig. 8. Prototype motor 


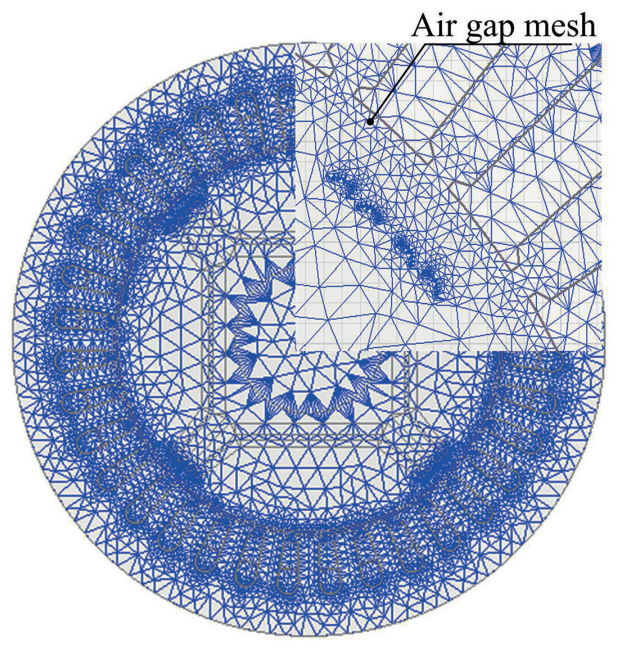

Fig. 9. Mesh plot

windings, PMs and shaft. Stator slots adopt semi-open plow shape, and each pole of the motor is composed of four pieces of PMs, which are embedded and composited. That is, two pieces of rectangular PMs are placed in radial direction, and two pieces of rectangular PMs are set in tangential direction. The detailed data of the proposed motor are shown in Table 1.

Table 1

Motor characteristics

\begin{tabular}{lcc}
\hline Parameter & Symbol & Value \\
\hline Stator material & - & DW360_50 \\
Stator outer diameter & $R s$ & $124 \mathrm{~mm}$ \\
Stator slots number & $Q$ & 36 \\
Torque windings pole pairs & $P_{M}$ & 2 \\
Suspension windings pole pairs & $P_{S}$ & 3 \\
Turns of torque windings per slot & $N a$ & 40 \\
Turns of suspension windings per slot & $N b$ & 25 \\
Airgap length & $\delta_{0}$ & $1 \mathrm{~mm}$ \\
Stator length & $l$ & $80 \mathrm{~mm}$ \\
Rotor material & - & $\mathrm{DW} 360 \_50$ \\
Rotor outer diameter & $R$ & $78 \mathrm{~mm}$ \\
Permanent magnetic material & - & $\mathrm{NdFe} 35$ \\
Coercive force & $H_{C}$ & $-890 \mathrm{KA} / \mathrm{m}$ \\
Magnet remanence at $20^{\circ} \mathrm{C}$ & $B r$ & $1.099 \mathrm{~T}$ \\
Tangential-set PM length & $d_{1} / d_{2}$ & $10.3 \mathrm{~mm} / 12.4 \mathrm{~mm}$ \\
Radial-set PM thickness & $H_{1} / H_{2}$ & $1.5 \mathrm{~mm} / 2.5 \mathrm{~mm}$ \\
\hline
\end{tabular}

Moreover, the mesh plot of the FEM model is shown in Fig. 9. It is well known that the quality of mesh modeling has a great effect on results of finite element analysis, especially the quality of air gap mesh - the denser air gap mesh, the more accurate the calculation. According to Fig. 9, it can be seen that air gap mesh is denser than other parts and meets the requirement of computational accuracy.
4.2. Magnetic field analysis. In this paper, two-dimensional (2D) FEM is used to determine the magnetic field distribution of the proposed machine. Magnetic fields in the proposed machine include those produced by PMs, torque windings and suspension windings. First, because of the complexed magnetic fields, the PMs, torque windings and suspension windings will be analyzed separately. Then, the composed magnetic fields are carried out. The illustration of PMs magnetic field is shown Fig. 10. In Fig. 10, it can be seen that magnetic flux density waveform in airgap is nearly sinusoidal, but it has large harmonic components. Furthermore, the airgap flux density reaches up to 0.7 T. The illustrations of the magnetic field produced by torque winding current $\left(i_{t}=1 \mathrm{~A}\right)$ and suspension current $\left(i_{s}=4 \mathrm{~A}\right)$ are shown Fig. 11 and Fig. 12, respectively. It can be seen that the four-pole magnetic flux is generated by PM and torque windings current, different from each other, and the suspension force windings current generate six-pole magnetic flux. When the rotor is not eccentric, the composed magnetic of proposed machine

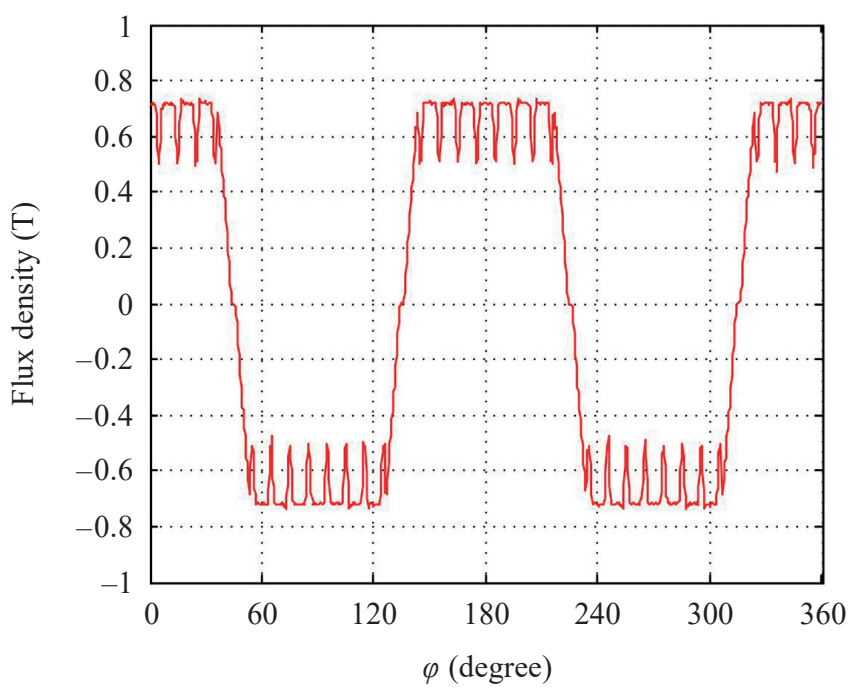

Fig. 10. Airgap magnetic flux density produced by PMs

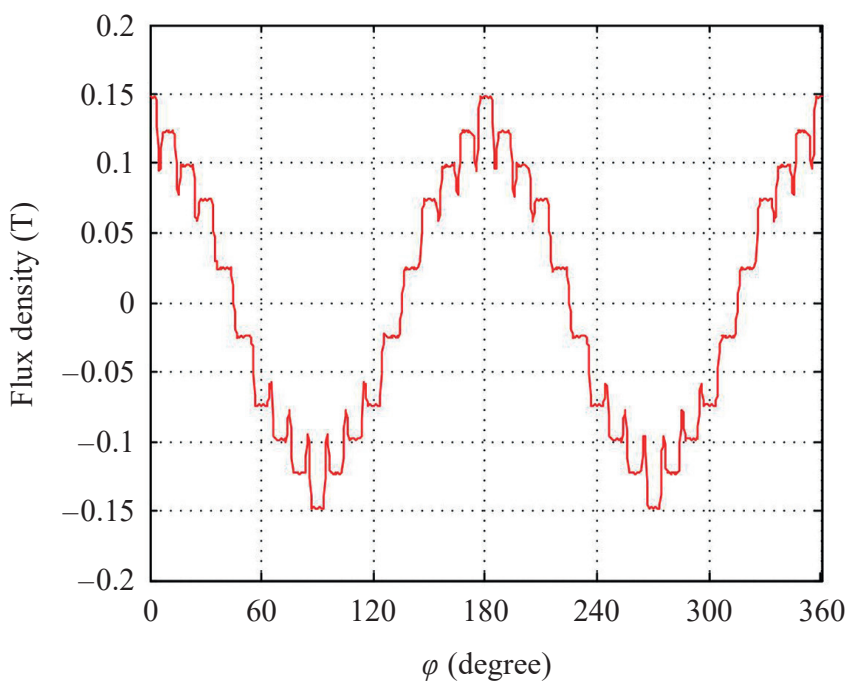

Fig. 11. Airgap magnetic flux density produced by torque winding 


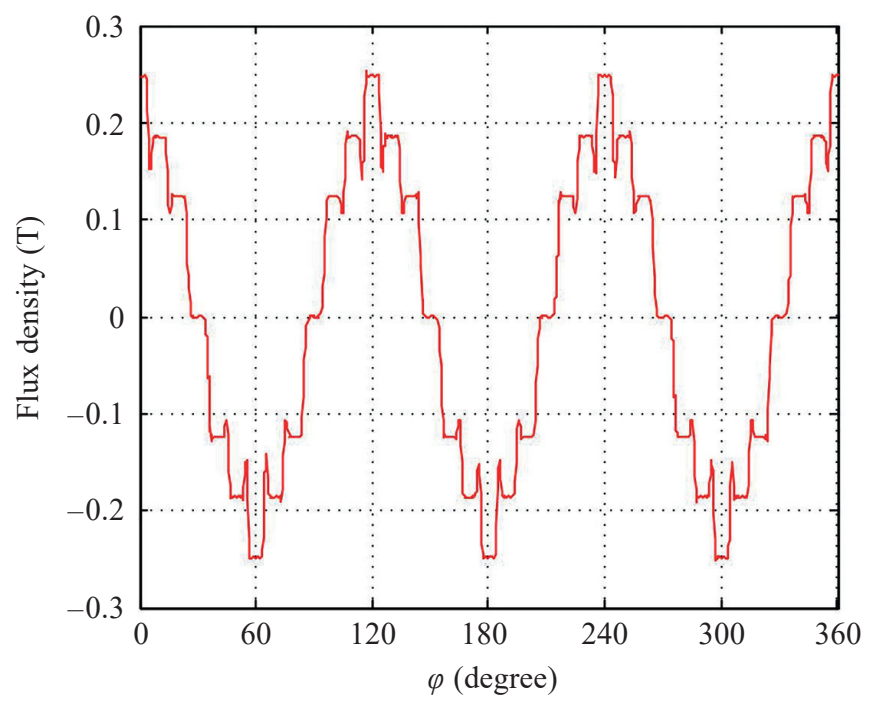

Fig. 12. Airgap magnetic flux density produced by suspension winding

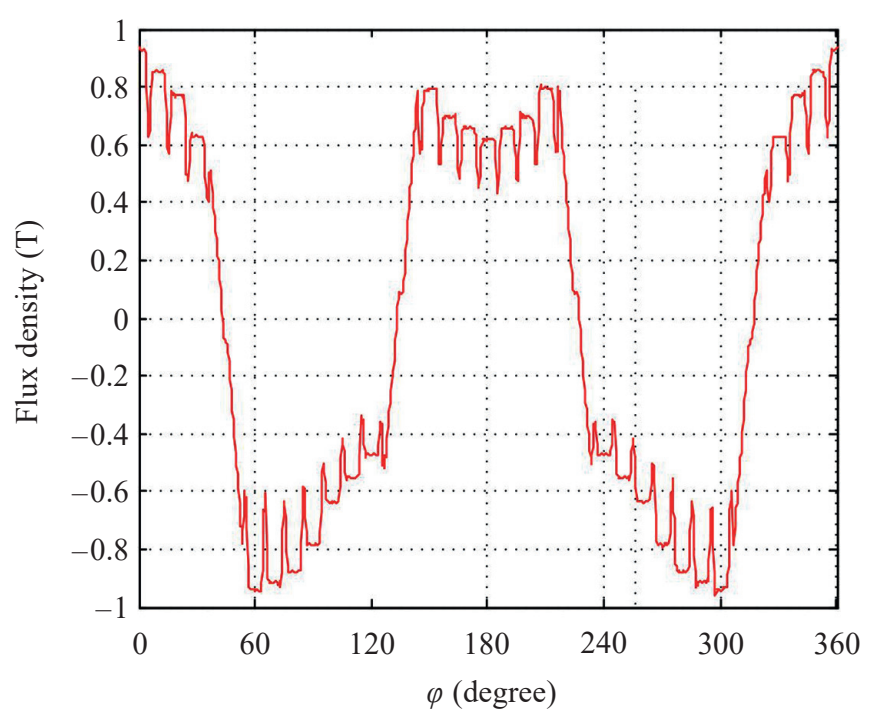

Fig. 13. Composed airgap magnetic flux density in proposed machine

produced by PMs, torque windings current $\left(i_{t}=1 \mathrm{~A}\right)$ and suspension windings current $\left(i_{s}=4 \mathrm{~A}\right)$ is shown in Fig. 13. According to Fig. 13, it can be seen that due to the interaction between aforementioned magnetic fields, the airgap flux density is increased in the airgap $\varphi=0$ (point 1 in Fig. 1a), and decreased in the airgap $\varphi=\pi$ (point 3 in Fig. 1a), which is consistent with the principle of suspension force generation in Section 2.

4.3. PM flux linkage. The PM flux linkage calculated by FEM is shown in Fig. 14. As shown in Fig. 14, the waveform of the PM flux linkage approach to sine wave and the PM flux linkage transform two cycles with rotor making one revolution; it shifts 60 mechanical degrees (i.e., 120 electrical degrees) between phase to phase. For instance, phase A differs by 60 mechanical degrees from phase B. In addition, a FFT analysis for phase A flux linkage with one period is used. From the harmonic amplitudes from first to eleventh shown in Fig. 15, it can be seen

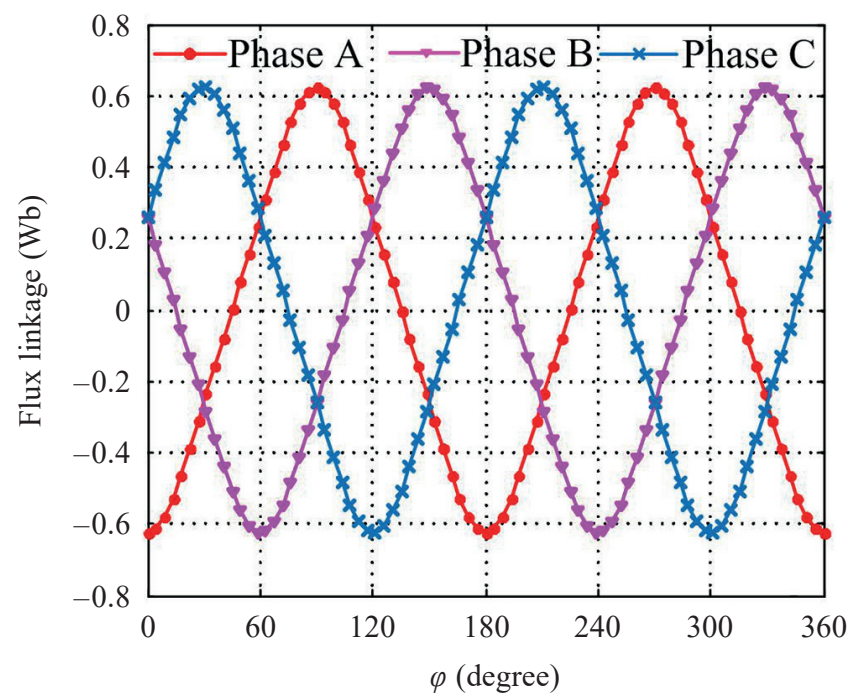

Fig. 14. Permanent magnet flux linkage

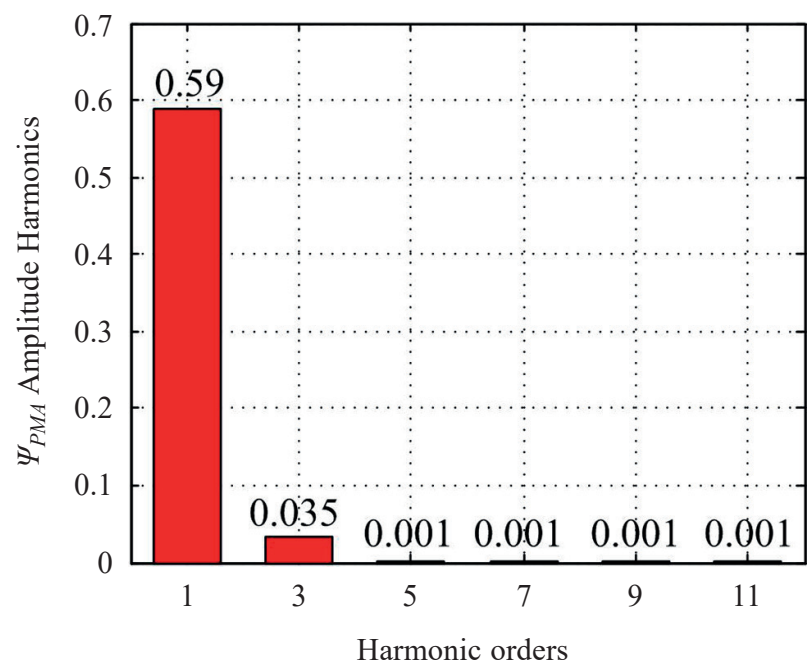

Fig. 15. Amplitude of fundamental wave and harmonics

that the harmonic only accounts for a small part. The proportion of high harmonic magnitudes and fundamental magnitude is very small, the total harmonic distortion (THD) is only $5.7 \%$, and the third-harmonic accounts for most of the total harmonic. Therefore, without considering the high harmonic, the threephase PM flux linkage $\Psi_{P M A}, \Psi_{P M B}$ and $\Psi_{P M C}$ still meet the requirement of computational accuracy.

4.4. Inductance. The inductance is one of the important technical parameters for the proposed motors, and it will have an important effect on radial suspension forces and output power. Therefore, for optimal design of proposed motor, it is important to calculate inductance accurately. In general the inductance can be given as

$$
L=\frac{\mathrm{d} \Psi}{\mathrm{d} i}
$$

where $\Psi$ is flux linkage produced by coil when providing an alternating current, $L$ is inductance and $i$ is current. 
Supposing that the suspension windings are not excited when calculating inductance, that is, the motor operates in the combined magnetic field of PM and torque windings. Taking phase $\mathrm{A}$ as an example, when phase A torque windings is excited, phase A torque windings self-inductance $L_{a a}$, the mutual-inductance $M_{b a}$ (between phase A and phase B) and the mutual-inductance $M_{c a}$ (between phase A and phase C) can be given as

$$
\left\{\begin{aligned}
L_{a a} & =\left(\Psi_{A}-\Psi_{P M A}\right) / i_{A} \\
M_{b a} & =\left(\Psi_{B}-\Psi_{P M B}\right) / i_{A} \\
M_{c a} & =\left(\Psi_{C}-\Psi_{P M C}\right) / i_{A}
\end{aligned}\right.
$$

In general, the inductance calculated by FEM can be divided into three steps [21]. Here, let us take the phase A as an example. First, we calculate the PM flux linkage $\Psi_{P M A}$ with no-load. Second, we provide current $i_{A}$ for phase A torque windings, and the combined flux linkage $\Psi_{A}$ produced by both PMs and phase A torque windings can be obtained. Finally, the inductance of phase A torque windings can be calculated according to (9).

Figure 16 shows the inductance waveform of three phases with saturated magnetic fields. As shown in Fig. 16, not only are the torque winding inductances the function of rotor position, but they also relate to the interaction between the PM magnetic field and the torque winding magnetic field. Taking phase A as example, when $\theta=0$ and $\theta=\pi$, the direction of PM flux linkage is parallel to phase A torque winding flux linkage, therefore, the saturation of phase A magnetic field is enhanced and increases to most saturated, and the inductance values are the minimum at this time. When $\theta=\pi / 2$ and $\theta=3 \pi / 2$, the direction of PM flux linkage is perpendicular to phase A torque winding flux linkage, and the saturation of phase A magnetic field is lowered and reaches the most unsaturated, and the inductance values are the maximum at this moment. Furthermore, when $\theta=0$, the direction of phase A torque winding magnetic field is against the PM magnetic field, which will weaken the

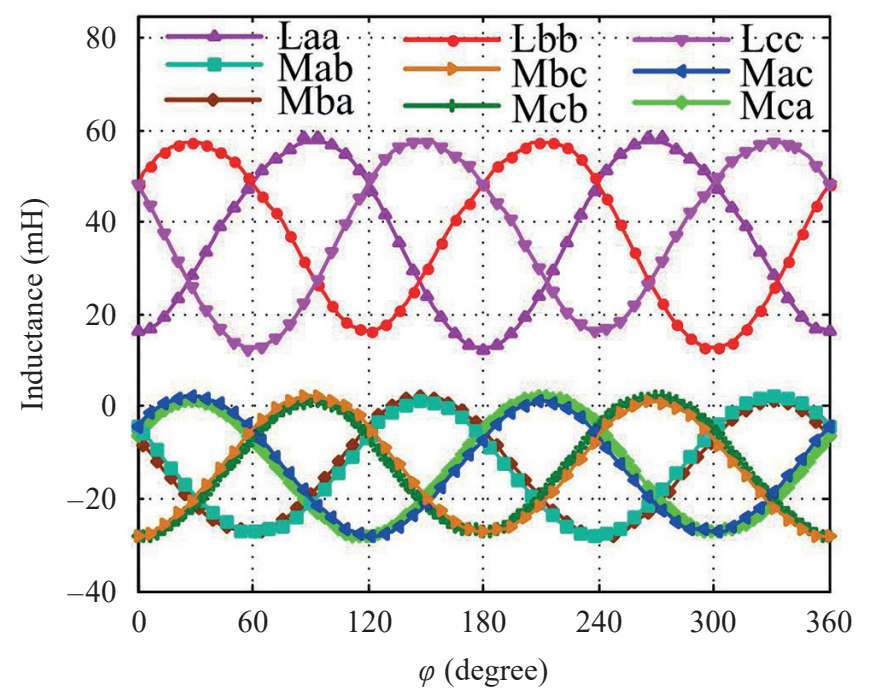

Fig. 16. Three-phase inductance of torque winding

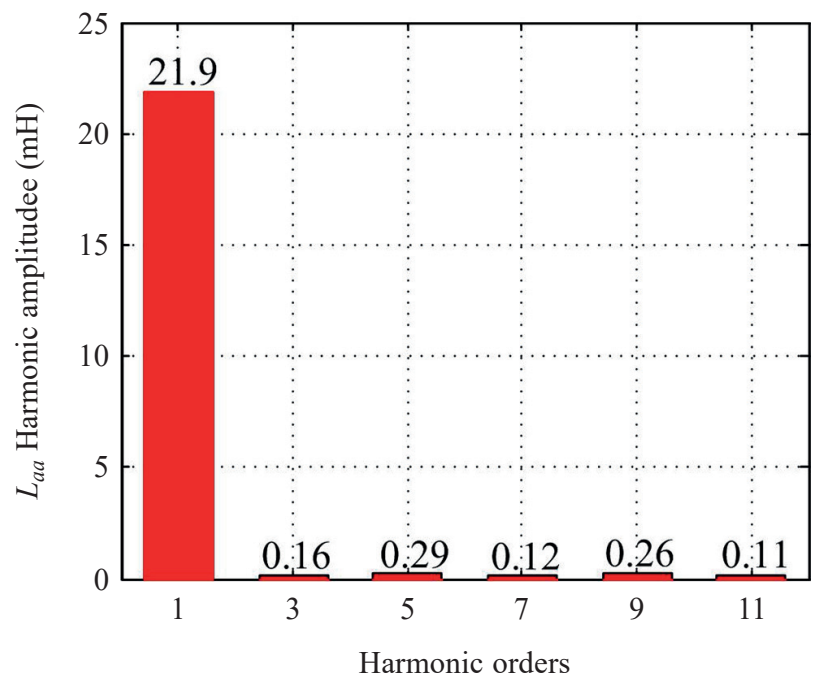

Fig. 17. Amplitude of the fundamental wave and high order harmonics of $L_{a a}$

PM magnetic field. It will lower the saturation of phase A magnetic field and enhance corresponding inductance values. As shown in Fig. 16, when $\theta=0$, the minimal value of inductance waveform $L_{a a}$ is $16 \mathrm{mH}$. On the contrary, when $\theta=\pi$, the phase A torque winding magnetic field will strengthen the PM magnetic field, which results in the more saturated magnetic field and smaller inductance values. It can be seen from Fig. 16 that minimal value of inductance waveform $L_{a a}$ is $12.4 \mathrm{mH}$ when $\theta=\pi$. Therefore, due to the magnetic field produced by torque winding, self-inductance $L_{a a}, L_{b b}$ and $L_{c c}$ are about $3.6 \mathrm{mH}$ different between the minimal waveform values.

Figure 17 shows the results of FFT analysis of phase A torque windings self-inductance. According to Fig. 17, it can be seen that the proportion of high harmonic magnitudes and fundamental magnitude is very small and the THD is only $4.3 \%$. In order to control the motor easily, the two phase rotating reference frame $\mathrm{d}$-q axis is widely used. The d-axis inductance $L_{d}$ and q-axis inductance $L_{q}$ can be calculated based on the three phase inductance according to (10).

$$
L(d, q, 0)=C_{3 / 2} L(a, b, c) C_{3 / 2}^{T},
$$

where $L(d, q, 0)=\left[\begin{array}{ccc}L d & L d q & L d 0 \\ L q d & L q & L d 0 \\ L 0 d & L 0 q & L 0\end{array}\right]$ is the inductance matrix in d-q axis, $L(a, b, c)=\left[\begin{array}{lll}L a a & L a b & L d c \\ L b a & L b b & L b c \\ L c a & L c b & L c c\end{array}\right]$ is the three phase inductance matrix of torque windings, and $C_{3 / 2}=\frac{2}{3}\left[\begin{array}{ccc}\cos & \cos (\theta-2 \pi / 3) & \cos (\theta+2 \pi / 3) \\ -\sin \theta & -\sin (\theta-2 \pi / 3) & -\sin (\theta+2 \pi / 3) \\ 1 / 2 & 1 / 2 & 1 / 2\end{array}\right]$

is the transformation matrix. 


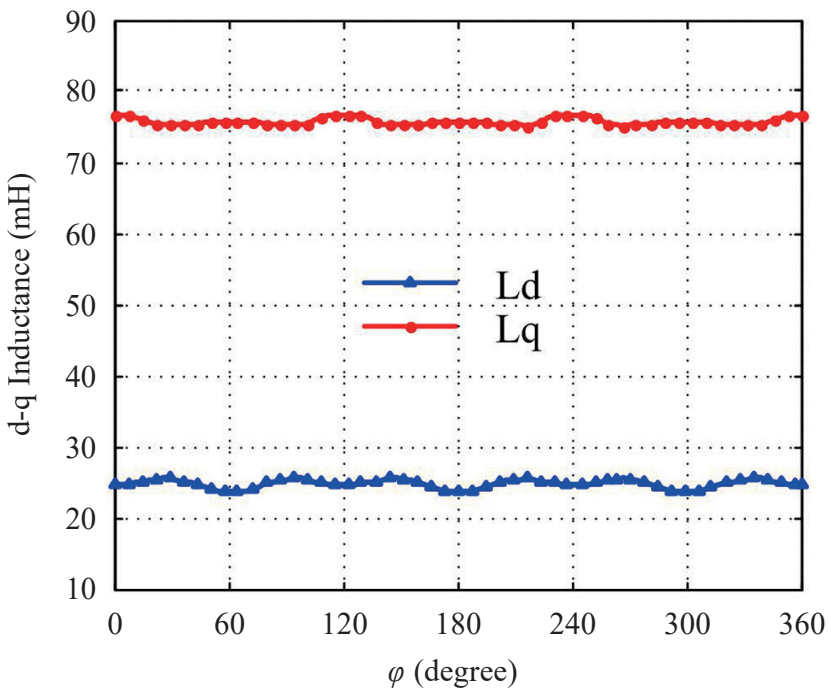

Fig. 18. d-q axis torque winding inductance

Figure 18 shows the d-q axis torque winding inductance. Because magnetic anisotropy exists in the rotor, the magnetic permeability of the PMs is close to air, and they can be considered as a part of the air gap. Thus, the reluctance in d-axis is much larger than q-axis. So, the q-axis inductance $L_{q}$ should be larger than d-axis inductance $L_{d}$. It can be concluded from Fig. 18 that the q-axis inductance $L_{q}$ is much larger than d-axis inductance $L_{d}$, which is consistent with the theory.

\section{Electromagnetic torque analysis}

In this section, the analytic equations of electronic torque including PM torque, reluctance torque and cogging torque are expressed. Then, the relationship between electromagnetic torque and power angle is investigated. Finally, the electromagnetic torque in the power angle giving the maximum torque is analyzed.

When the rotor is in center location, the electromagnetic torque $T_{e m}$ of proposed motor can be written as

$$
T_{e m}=T_{p m}+T_{r}+T_{c o g},
$$

where $T_{p m}, T_{r}, T_{c o g}$ are the PM torque, reluctance torque and cogging torque, respectively. According to the preceding analysis, it is known that the cogging torque only causes torque ripple. Therefore, the effective torque of electromagnetic torque consist of PM torque $T_{p m}$ and reluctance torque $T_{r}$. PM torque $T_{p m}$ is produced by the PMs and q-axis torque winding current. Reluctance torque $T_{r}$ is produced by non-equal reluctance between d-axis and q-axis. The PM torque $T_{p m}$ and reluctance torque $T_{r}$ can be given as follows:

$$
\begin{gathered}
T_{p m}=\frac{3}{2} P_{M} \Psi_{p m} i_{q} \\
T_{r}=-\frac{3}{2} P_{M}\left(l_{d}-l_{q}\right) i_{d} i_{q} .
\end{gathered}
$$

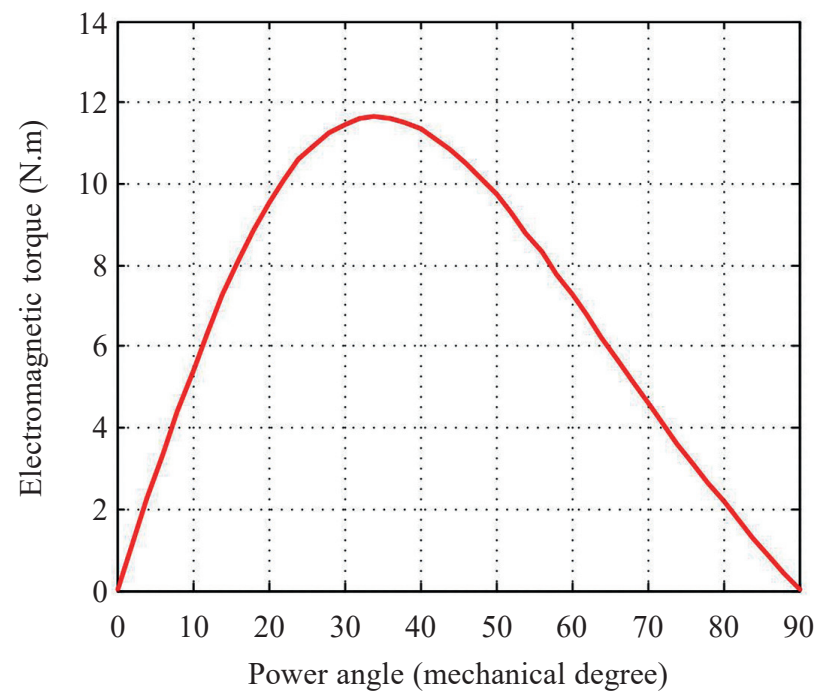

Fig. 19. Electromagnetic torque versus the power angle

The relative position of rotating magnetic field rotor has an important effect on electromagnetic torque characteristics of motor. The electromagnetic torque of proposed machine versus the power angle is illustrated in Fig. 19, where the toque winding current is $6 \mathrm{~A}$ and the suspension winding current is $4 \mathrm{~A}$. It should be emphasized that the cogging torque is very small because of the optimization in Section 3, and the cogging torque is neglected in this figure. In Fig. 19, it can be seen that the maximum value of the electromagnetic torque is encountered in $34^{\circ}$ ( 68 electrical degrees), which should be taken into consideration for control purposes. It also can be seen that Fig. 19 is asymmetrical. The reason is that the air gap in rotor topologies of proposed machine is asymmetrical, and it can cause saliency of machine.

According to aforementioned results, the proposed machine is simulated in synchronous operation for the power angle giving the maximum torque. The electromagnetic torque versus the mechanical degree is shown in Fig. 20. According to

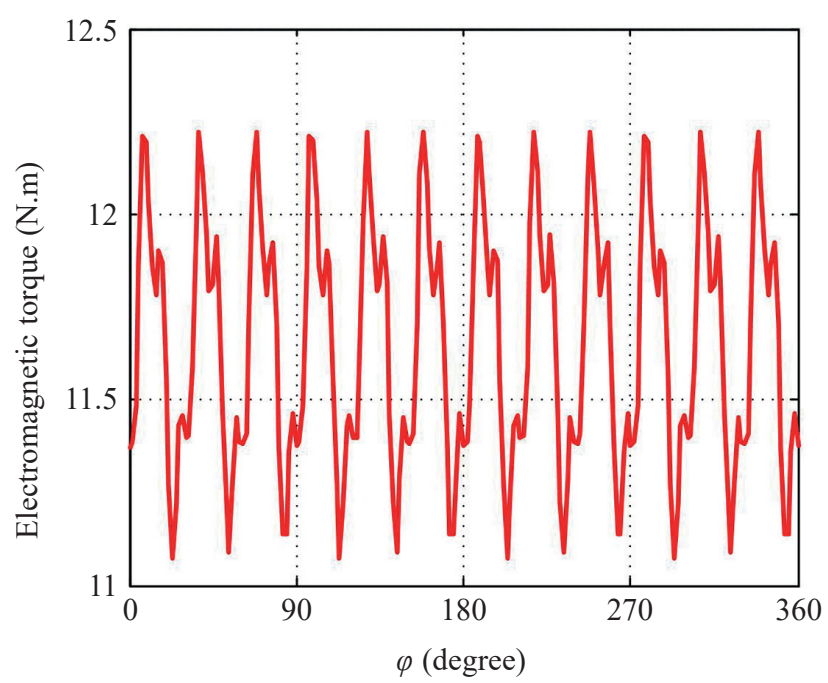

Fig. 20. Electromagnetic torque versus mechanical degree 
Fig. 20, it can be seen that the maximal electromagnetic torque is $12.2 \mathrm{~N} . \mathrm{m}$, the minimal torque is $11.1 \mathrm{~N} . \mathrm{m}$, and the mean value of electromagnetic torque is $11.7 \mathrm{~N} . \mathrm{m}$. The proposed machine has large electromagnetic torque. That is because the tangential-set PMs can create high magnetic flux density in the air gap, which produces large electromagnetic torque. In addition, the feature of the rotor saliency also contributes to the electromagnetic torque. Remarkably, the electromagnetic torque ripple is only $9 \%$. This phenomenon results from the fact that the proposed machine has smaller cogging torque after optimizing.

\section{Suspension force characteristics}

In this section, in order to obtain accurate mathematical model of radial suspension force, Maxwell's stress tensor method is used for proposed motors. Then, the theoretical calculation result and the FEM calculation result are compared when different currents are provided. Also, the relation between suspension fore and power angle of proposed motor is investigated. Finally, the kind of effects that the optimization has on suspension force is discussed.

When rotor eccentricity does not occur, the suspension force $F_{p}$ can be obtained as follow

$$
F_{p}=\sqrt{F_{x}^{2}+F_{y}^{2}}
$$

where $F_{x}$ and $F_{y}$ are suspension force along x-axis and y-axis, respectively. And it can be given as

$$
\begin{aligned}
& F_{x}=k_{\alpha} I_{S} I_{P M} \cos \left(\theta_{M}-\theta_{S}\right) \\
& F_{y}=k_{\alpha} I_{S} I_{P M} \sin \left(\theta_{M}-\theta_{S}\right)
\end{aligned}
$$

where $k_{\alpha}=\frac{3 \operatorname{lr} \mu_{0} N_{S} N_{M} k_{d S} k_{d M}}{4 \pi \delta_{0}^{2}}, l$ is the effective rotor length, $r$ is the rotor outer surface radius, $\mu_{0}$ is the permeability in the vacuum, $N_{S}$ and $N_{M}$ are the coil numbers of suspension windings and coil numbers of torque windings per phase, respectively; $k_{d M}$ and $k_{d S}$ are the torque windings and suspension windings stacking coefficient respectively; $\delta_{0}$ is the airgap length when rotor eccentricity is not the case, $I_{S}$ is suspension winding current and $I_{P M}$ is the equivalent current of PM; $\theta_{M}$ and $\theta_{S}$ are the initial angle of torque winding current and initial angle of suspension winding current, respectively.

Figure 21 shows the relation of suspension force to suspension windings current. The simulated values are compared with theoretical results in different currents. According to Fig. 21, it can be seen that with the suspension current increasing, the suspension force increases. In addition, the simulated result are identical with theoretical results when providing small suspension current; with the increase of suspension current, the simulated results deviate from the theoretical one, which is affected by the saturation of magnetic field.

The suspension force of proposed machine versus the power angle is shown in Fig. 22 where the toque winding current is

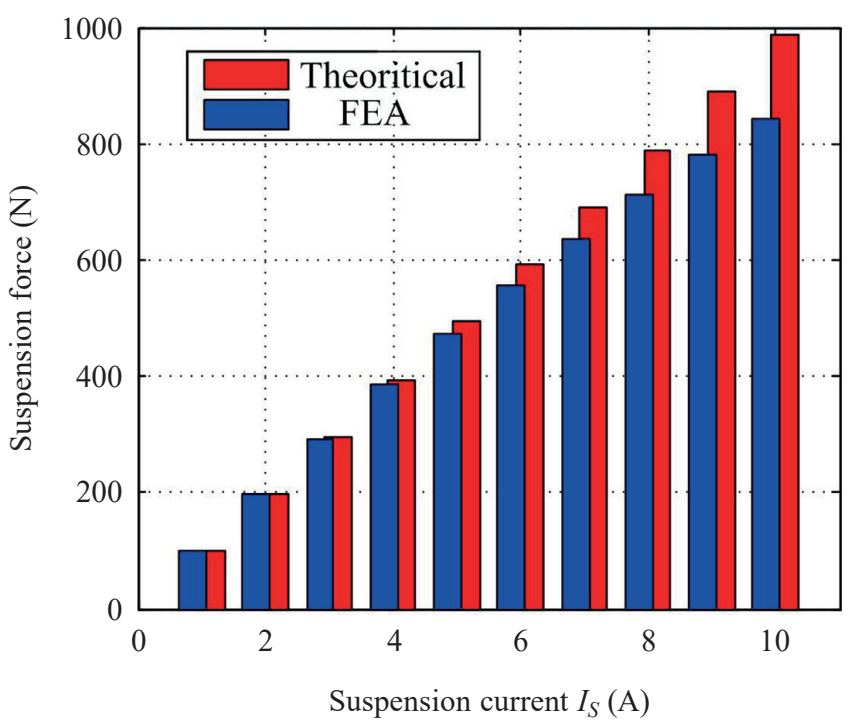

Fig. 21. Suspension force versus $I_{S}$

$6 \mathrm{~A}$ and the suspension winding current is $4 \mathrm{~A}$. It can be seen that the maximum value of the suspension force is encountered in $90^{\circ}$ (mechanical degrees), and the minimum value of the suspension force is encountered in $0^{\circ}$ (mechanical degrees). In $34^{\circ}$ (mechanical degrees) where the maximum value of the electromagnetic torque is taken, the suspension force reaches up to $353.5 \mathrm{~N}$, which satisfies the requirement of rotor floating steadily.

In Section 3, in order to eliminate the torque ripple, the size of two tangential-set PMs is optimized. In this section, effects of the optimization on suspension force are discussed. According to (15), it is obvious that the equivalent current of PM is proportional to suspension force, and $I_{P M}$ will change with the geometry parameters of two tangential-set PMs. Figure 23 shows

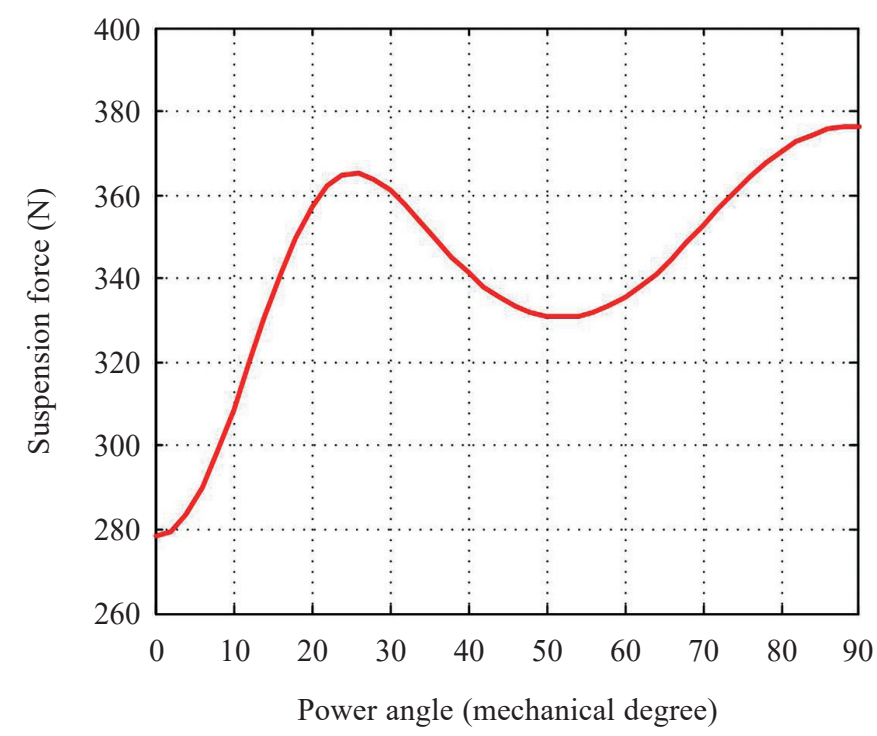

Fig. 22. Suspension force versus the power angle 


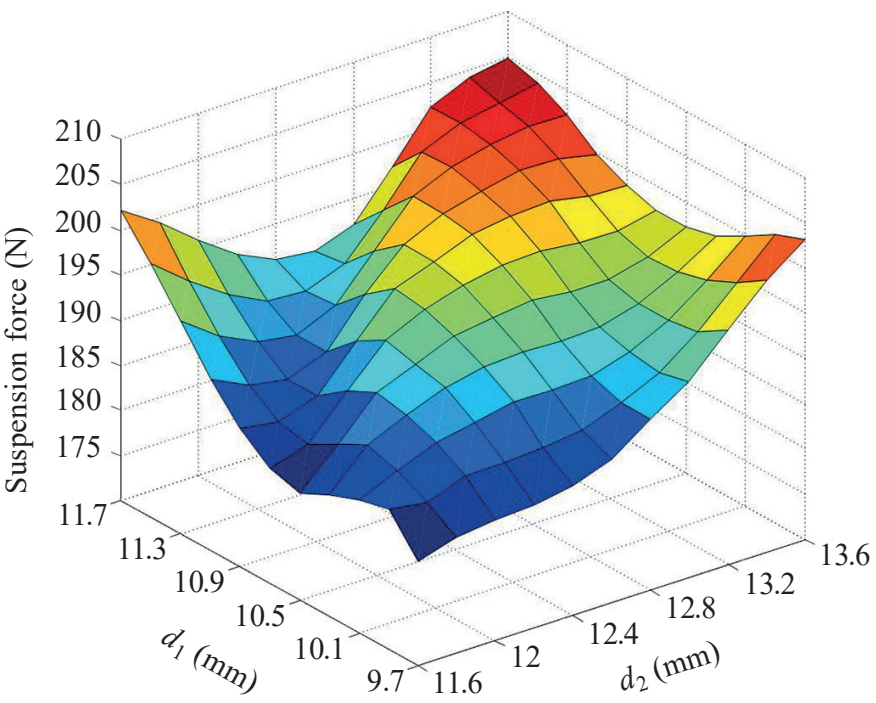

Fig. 23. Relation between suspension force and two tangential-set PMs

the relation between the suspension force and the geometry parameters of two tangential-set PMs when injecting 2 A current into the suspension force windings. According to Fig. 23, the suspension force, on the whole, is enhanced along with the increase of the length of two tangential-set PMs. Furthermore, it can also be seen that the tangential-set PMs have little influence on the suspension force, and it is trivial as compared with the advantages of reducing torque ripple. The value of suspension force in the optimal point of cogging torque is $191.9 \mathrm{~N}$, which satisfies the requirement of rotor floating steadily.

\section{Conclusion}

In this paper, the interior composite-rotor BPMSM with two layer PMs is proposed. In order to reduce torque ripple in proposed motors, the size of PM is optimized by using Ansoft. Then the static electromagnetic characteristics are analyzed, and simulation results are listed. Concerning magnetic field, the PMs fields and torque windings magnetic fields are interfered with by suspension windings magnetic field, which is why the flux density in airgap $\varphi=0$ is greater than $\varphi=\pi$. About PM flux linkage, the third order harmonic has significant influence on the PM flux linkage. Inductance is not only a function of rotor position, but it is also influenced by interaction with torque windings flux linkage and PM flux linkage. As concerns electromagnetic torque, cogging torque only causes torque ripple, and the proposed rotor topologies may not only increase the electromagnetic torque, but also reduce the electromagnetic torque ripple. As for suspension force, calculated results of suspension force fit well the simulation results. In the power angle producing the maximum torque, the suspension force satisfies the requirement of rotor floating steadily. In addition, during the optimization of the torque ripple, the suspension force is influenced slightly by different length of two tangential-set PMs, which is trivial as compared with the gains in reduction of torque ripple. These results provide a favorable theoretical foundation for optimization design and further study of the interior composite-rotor BPMSM with two layer PMs.

Acknowledgements. This work was supported in part by the National Natural Science Foundation of China under Projects 51305170 and 51475214, by the Natural Science Foundation of Jiangsu Province under Projects BK20170071 and BK20141301, by the China Postdoctoral Science Foundation under Project 2016M601726 and 2015T80508,by the Six Categories Talent Peak of Jiangsu Province under Projects 2015-XNYQC-003, 2014-ZBZZ-017 and 2016-GDZB-096, Zhenjiang Key Research and Development Project under Project GY2016003, by the Key Project of Natural Science Foundation of Jiangsu Higher Education Institutions under Project 17KJA460005, by the "333 project" of Jiangsu Province under Project BRA2017441, and by the Priority Academic Program Development of Jiangsu Higher Education Institutions (PAPD).

\section{REFERENCES}

[1] X. Sun, B. Su, L. Chen, Z. Yang, X. Xu, and Z. Shi, "Precise control of a four degree-of-freedom permanent magnet biased active magnetic bearing system in a magnetically suspended direct-driven spindle using neural network inverse scheme", Mechanical Systems and Signal Processing 88, 36-48 (2017).

[2] X. Sun, Z. Shi, L. Chen, and Z. Yang, "Internal model control for a bearingless permanent magnet synchronous motor based on inverse system method", IEEE Transactions on Energy Conversion 31(4), 1539-1548 (2016).

[3] X. Sun, L. Chen, H. Jiang, Z. Yang, J. Chen, and W. Zhang, "High-performance control for a bearingless permanent magnet synchronous motor using neural network inverse scheme plus internal model controllers", IEEE Transactions on Industrial Electronics 63(6), 3479-3488 (2016).

[4] X. Sun, B. Su, L. Chen, Z. Yang, J. Chen, and W. Zhang, "Nonlinear flux linkage modeling of a bearingless permanent magnet synchronous motor based on AW-LSSVM regression algorithm," International Journal of Applied Electromagnetics and Mechanics 51(2), 151-159 (2016).

[5] K. Raggl, B. Warberger, T. Nussbaumer, S. Burger, and J. Kolar, "Robust angle-sensorless control of a PMSM bearingless pump", IEEE Transactions on industrial ececronics 56, 2076-2085 (2009).

[6] W. Li, K.T. Chau, T.W. Ching, Y. Wang, M. Chen, "Design of a high-speed superconducting bearingless machine for flywheel energy storage systems", IEEE Transactions on Applied Superconductivity 25(3), 5700204 (2015).

[7] P. Bogusz, "A switched reluctance motor control method limiting the maximum dc source current in the low-speed range," Bull. Pol. Ac.: Tech. 64(1), 197-206 (2016).

[8] H. Wang, J. Liu, J. Bao, and B. Xue, "A novel bearingless switched reluctance motor with a biased permanent magnet”, IEEE Transactions on Industrial Electronics 61(12), 6947-6955 (2014).

[9] X. Sun, L. Chen, Z. Yang, and H. Zhu, "Speed-sensorless vector control of a bearingless induction motor with artificial neural network inverse speed observer", IEEE/ASME Transactions on Mechatronics 18(4), 1357-1366 (2013).

[10] C.T. Kowalski, and M. Kaminski, "Rotor fault detector of the converter-fed induction motor based on RBF neural network", Bull. Pol. Ac.: Tech. 62(1), 69-76 (2014). 
[11] X. Sun, L. Chen, Z. Yang, and H. Zhu, "Analysis of inductance characteristics for a bearingless permanent magnet synchronous motor”, Electrical Engineering 95(3), 277-286 (2013).

[12] X. Sun, L. Chen and Z. Yang, "Overview of bearingless permanent-magnet synchronous motors", IEEE Transactions on Industrial Electronics 60(12), 5528-5538 (2013).

[13] K. Ahn, A.E. Bayrak, and P.Y. Papalambros, "Electric vehicle design optimization: Integration of a high-fidelity interior-permanent-magnet motor model", IEEE Transactions on Vehicular Technology 64(9), 3870-3877 (2015).

[14] A. Tessarolo, M. Mezzarobba, and R. Menis, "Modeling, analysis, and testing of a novel Spoke-Type interior permanent magnet motor with improved flux weakening capability", IEEE Transactions on Magnetics 51(4), 1-10 (2015).

[15] M. Mirzaei, S.E. Abdollahi, and H. Lesani, "A large linear interior permanent magnet motor for electromagnetic launcher", IEEE Transactions on Plasma Science 39(6), 1566-1570 (2011).

[16] S. Kim, J.-Y. Lee, Y.-K. Kim, J.-P. Hong, Y. Hur, and Y.-H. Jung, "Optimization for reduction of torque ripple in interior permanent magnet motor by using the taguchi method", IEEE Transactions on Magnetics 41(5), 1796-1799 (2005).
[17] J. Kwack, S. Min, and J. Hong, "Optimal stator design of interior permanent magnet motor to reduce torque ripple using the Level Set method", IEEE Transactions on Magnetics 46(6), 2108-2111 (2010).

[18] X. Sun, L. Chen, Z. Yang, H. Zhu, W. Zuo, and K. Shi, "Modeling of a bearingless permanent magnet synchronous motor considering rotor eccentricity and coupling relationship of windings," Dian gong Ji shu Xue bao/Transactions of China Electrotechnical Society 28, 63-73 (2013), [in Chinese].

[19] X. Cao, Z. Deng, G. Yang, Y. Yang, and X. Wang, "Mathematical model of bearingless switched reluctance motors based on Maxwell stress tensor method," Zhongguo Dianji Gongcheng Xuebao/Proceedings of the Chinese Society of Electrical Engineering 29, 78-83 (2009), [in Chinese].

[20] S. Berhausen and S. Paszek, "Use of the finite element method for parameter estimation of the circuit model of a high power synchronous generator", Bull. Pol. Ac.: Tech. 63(3), 575-582 (2015).

[21] X. Sun, S. Luo, L. Chen, R. Zhao, and Z. Yang, "Suspension force modeling and electromagnetic characteristics analysis of an interior bearingless permanent magnet synchronous motor", Progress In Electromagnetics Research B. 69, 31-45 (2016). 